\title{
Analyses of Harvest Strategies for Pandalid Shrimp Populations
}

\author{
Caihong Fu ${ }^{1}$ and Terrance J. Quinn II \\ Juneau Center, School of Fisheries and Ocean Sciences, University of Alaska Fairbanks \\ 11120 Glacier Highway, Juneau, AK 99801-8677 USA \\ Gordon H. Kruse \\ Alaska Department of Fish and Game, Division of Commercial Fisheries \\ P. O. Box 25526, Juneau, AK 99802-5526 USA
}

\begin{abstract}
Harvest strategies for the northern shrimp (Pandalus borealis) population in Kachemak Bay, Alaska, were analyzed using a length-based population model under various levels of instantaneous fishing mortality $(F)$ and a biomass-based management threshold (BBMT). With constant instantaneous natural mortality $(M) \leq 0.4$ or constant recruitment $(R)$, threshold management, i.e. closing the fishery at population levels below BBMT, is unnecessary when the fishery is managed with an optimal fishing mortality rate $\left(F_{o p t}\right)$. However, for a population with a Beverton-Holt recruitment relationship, threshold management is essential to reduce the risk of population extinction. The robustness of establishing guideline levels for $F$ to misspecification of $M$ and $R$ was examined with values of $M$ and $R$ set higher than, lower than, or equal to their perceived true levels. Assessment surveys were assumed to occur once every 1 to 3 years. Underestimation of $M$ results in $F_{o p t}$ values associated with higher cumulative yield and higher risk of falling below population-at-risk threshold taken to be $20 \%$ of virgin spawning stock biomass. More frequent surveys help to reduce this risk. On the other hand, misspecification of $R$ has very little effect on forecasting population abundance if the population is sampled annually. Less frequent sampling induces higher risk if $R$ is specified too high, but it has little effect if $R$ is specified too low. In conclusion, frequent sampling and good understanding of $M$ are essential for sound management of fisheries such as those for northern shrimp in Kachemak Bay.
\end{abstract}

Key words: Alaska area, assessment, management, mortality, shrimp

\section{Introduction}

Patterns of recruitment, maturity and growth affect optimal harvest strategies (Clark, 1991), and harvest strategies should be explored on a species or population-specific basis rather than relying on general results (Sigler and Fujioka, 1993). In this paper, we examined harvest strategies for northern shrimp (Pandalus borealis) based on population parameters and features of recruitment and natural mortality obtained for the Kachemak Bay, Alaska, population (Fu et al., 1999). Monte Carlo simulations with a length-based population model modified from Quinn et al. (1998) were employed to evaluate harvest strategies.
Northern shrimp in Kachemak Bay were harvested intermittently with small landings in the 1950s and 1960s (Davis, MS 1982). Since 1971, annual trawl surveys were carried out to obtain population biomass indices. Based on historical landing information and biomass surveys, the annual guideline yield level, the target yield established prior to the fishery, was set at 2270 tons for years from 1971 to 1977 with an exception of 2500 tons for the year 1972. The guideline yield level was increased to about 2700 tons during the next three years (Davis, MS 1982). In 1971 the actual yield was about 2000 tons, and yields during the next few years remained near that level (Fig. 1). During 1978 to 1980 yields increased significantly corresponding to the increases in guideline levels.

1 Current address: Marine Fish Division, Department of Fisheries and Oceans, P. O. Box 1006, Dartmouth, Nova Scotia, B2Y 4A2, Canada 

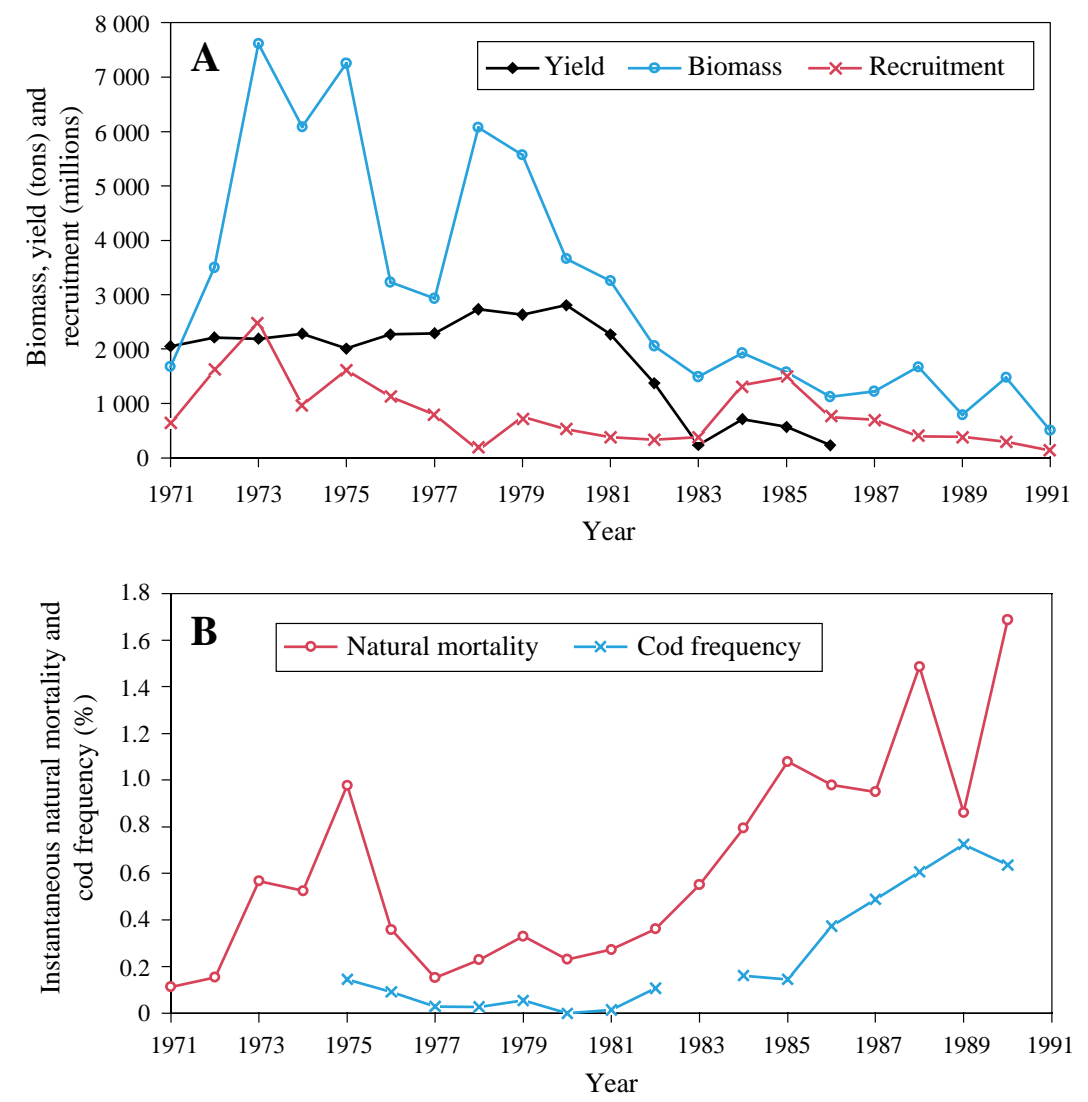

Fig. 1. (A) Observed yield, survey biomass estimates and estimated recruitment for the northern shrimp population in Kachemak Bay; (B) estimated instantaneous natural mortality and frequency of cod occurrence in numbers obtained from the same surveys.

Ironically, landings declined sharply in 1982 despite the fact that the Alaska Board of Fisheries concluded that the stock appeared capable of sustaining an annual yield of 2270 tons (Davis, MS 1982). Subsequently, a low population biomass estimate resulted in partial closure of the fishery in 1983. The fishery was completely closed in the autumn of 1986 due to continued low stock size (Gustafson, 1994), and since then surveys have indicated no sign of stock recovery.

The decline of the northern shrimp population in Kachemak Bay may have been part of the serial depletion experienced by many other crustacean populations in Alaskan waters in the early-1980s that included red king crab on the continental shelf around Kodiak Island (Orensanz et al., 1998). Northern shrimp is a major prey of Pacific cod (Gadus macrocephalus, Albers and Anderson, 1985). The continued high level of cod and other groundfish populations since the early-1980s has been implicated in the failure of the the northern shrimp population (Bechtol, 1997) to recover. Annual recruitment ( $R$, defined as abundance of age 1 shrimp) estimates from a length-based population model were low during the late-1970s and early-1980s, but rebounded somewhat in the mid-1980s (Fu et al., 1999; Fig. 1). On the other hand, estimated instantaneous natural mortality $(M)$ values from the same model increased sharply since the early-1980s. Our research was motivated by questions about the implications of these patterns in $R$ and $M$ on fishery management, specifically whether the shrimp population decline could have been averted by remedial regulatory actions.

The ultimate goal of harvest strategy analysis is to define a guideline level (GL) for yield, effort, or $F$ to be established in advance of the fishery. The determination of an optimal GL is dependent on three major factors: $R, M$ prior to fishing, and present population status. The first two factors are beyond human control and are usually subject to high variation and uncertainty. In this paper, we specifically compare 
optimal harvest strategies under different assumptions about $R$ and $M$ to assess their potential impacts on the population's response to exploitation. Because assessment surveys have been reduced from annual to triennial in the face of fishery closures and budget constraints, we also examine the effects of survey frequency on population projections and fishery management. Our objective was not to develop optimal GLs for specific situations, but rather to provide insights about how to establish GLs that are robust to uncertainties about the underlying population dynamics.

\section{Materials and Methods}

\section{Length-based population model}

The simulation for evaluating harvest strategies for pandalid shrimp was based on a length-based population model that follows each cohort throughout its life history (Quinn et al., 1998). The model follows the population from recruitment, assuming that the length frequency at recruitment is a simple discrete normal distribution $\left(N_{D}\right)$, to a maximum age of 6 years, assuming there is no survival above age 6 . The probability density function for the lengths $x$ at recruiting age $r$ of 1 and at the start of time $t$ is:

$$
\begin{aligned}
& f_{r t}(x) \sim N_{D}\left(\mu_{r, t}, \sigma_{r}^{2}\right)=e^{-\frac{1}{2 \sigma_{r}^{2}}\left(x-u_{r, t}\right)^{2}} / \xi_{r, t} \\
& \text { where } \xi_{r, t}=\sum_{x} e^{-\frac{1}{2 \sigma_{r}^{2}}\left(x-u_{r, t}\right)^{2}}
\end{aligned}
$$

Parameter $\mu_{r, t}$ is the mean length at age $r$ and time $t$, and $\sigma_{r}$ is the deviation of the length frequency normal distribution at age $r$. The abundance of the newly recruited shrimp at length $x$ is:

$$
N_{r, t}(x)=N_{r, t} \cdot f_{r, t}(x)
$$

The recruited shrimp and those at older ages are modelled to go through a growth and natural death process before they are subject to fishing. The standard von Bertalanffy growth model is used to express the growth pattern from one age to the next, assuming that growth is constant over time:

$$
L_{a+1}=L_{\infty}(1-\rho)+\rho L_{a}+\varepsilon
$$

where $\rho=e^{-k}$ is the Brody coefficient, and $\varepsilon \sim N\left(0, \sigma^{2}\right)$. $L_{\infty}$ is the asymptotic length, and $\kappa$ is a curvature parameter, governing the speed to approach $L_{\infty}$. Expected length after growth is then $\mu_{a+1, t+1}$ $=L_{\infty}(1-\rho)+\rho \mu_{a, t}$ and the expected variance after growth is:

$$
\sigma_{a+1}^{2}=\rho^{2} \sigma_{a}^{2}+\sigma^{2}
$$

After growth but before mortality, the relative distribution of lengths $\rho_{a^{\prime} t^{\prime}}(L)$ is:

$$
\rho_{a^{\prime}, t^{\prime}}(L)=\sum_{x} f_{a, t}(x) e^{-\frac{1}{2 \sigma_{a+1}^{2}}\left(L-\mu_{a+1, t+1}(x)\right)^{2}}
$$

After growth and natural death during the specific time $t$ period, the abundance $N_{a, t}(x)$ of age $a$ shrimp at length $x$ and at time $t$ (starting at age $r$ ) becomes $N_{a^{\prime}, t^{\prime}}(x)$ :

$$
N_{a^{\prime}+1, t^{\prime}+1}(x)=N_{a^{\prime}, t^{\prime}} P_{a^{\prime}, t^{\prime}}(x) e^{-M_{t}}
$$

Given instantaneous fishing mortality $F_{t}$ at ages of full recruitment, the abundance at age $a+1$ at the start of time $t+1, N_{a+1, t+1}(x)$, after growth, natural death and fishing mortality is:

$$
N_{a+1, t+1}(x)=N_{a^{\prime}, t^{\prime}}(x) e^{-F_{t} s_{X}}
$$

where $s_{x}$ is the selectivity function that follows the logistic curve:

$$
s_{x}=\frac{1}{1+e^{-\gamma\left(x-L_{50}\right)}}
$$

Parameter $\gamma$ is the shape parameter, and $L_{50}$ is the length at which $50 \%$ of the individuals are vulnerable to fishing.

Catch at age $a$ and during time $t$ is:

$$
C_{a, t}(x)=N_{a^{\prime}, t^{\prime}}(x)\left(1-e^{-F_{t} s_{x}}\right)
$$

Population biomass and yield are obtained from the sum of abundance and catches across all ages multiplied by weight at length, which has a relation of $W_{x}=a_{w} x^{b} w$. Exploitable biomass and yield are expressed as:

$$
\begin{gathered}
B_{t}=\sum_{x} \sum_{a} N_{a, t}(x) W_{X} S_{X} \\
Y_{t}=\sum_{x} \sum_{a} C_{a, t}(x) W_{X}
\end{gathered}
$$


For simplicity, maturity is assumed as lengthindependent within the same age. Female spawning stock biomass (SSB) at time $t$ is defined as:

$$
S S B_{t}=\omega_{t} \sum_{x} \sum_{a} \lambda_{a} N_{a, t}(x) W_{x}
$$

where $\varpi_{t}$ is equal to 1.0 if the number of males exceeds that of females, otherwise $\varpi_{t}$ is the sex ratio (male to female) in year $t$ :

$$
\varpi_{t}=\frac{\sum_{x} \sum_{a=2}\left(1-\lambda_{a}\right) N_{a, t}(x) W_{x}}{\sum_{x} \sum_{a=2} \lambda_{a} N_{a, t}(x) W_{x}}
$$

Parameter $\lambda_{a}$ is the proportion of females at age $a$. Northern shrimp do not "spawn" by dispersing reproductive products in the water, but instead they copulate and females carry eggs until they hatch. However, we liberally use the term SSB as a matter of convenience and convention with fish population dynamic models. We assumed northern shrimp in Kachemak Bay are males at ages 2 to 3 and then transform into females, i.e. $\lambda_{2}=\lambda_{3}=0.0$ and $\lambda_{4}=\lambda_{5}=\lambda_{6}=1.0$.

\section{Stochastic simulation}

The northern shrimp population in Kachemak Bay, Alaska, was simulated with a spawner-recruit relationship, growth, gear selectivity and the weightat-length relationship with parameters estimated for this population by $\mathrm{Fu}$ et al. (1999; Table 1). Each simulation started with an unexploited population at equilibrium that is harvested for 23 years, equivalent to the period from 1978, when there was a climate

TABLE 1. Parameters of spawner-recruit $(\alpha, \beta, \phi)$, growth $\left(L_{\infty}, \kappa, \sigma, \sigma_{r}\right)$, selectivity $\left(L_{50}, \gamma\right)$ and weight-atlength relationships $\left(a_{W}, b_{W}\right)$ estimated by $\mathrm{Fu} e t$ al. (1999) and used in the simulations.

\begin{tabular}{lc}
\hline \hline Parameters & Estimates \\
\hline$\alpha$ & 1.826 \\
$\beta$ & 0.002 \\
$\phi$ & 0.267 \\
$L_{\infty}$ & 24.698 \\
$\kappa$ & 0.367 \\
$\sigma$ & 0.529 \\
$\sigma_{r}$ & 1.127 \\
$L_{50}$ & 16.720 \\
$\gamma$ & 0.572 \\
$a_{W}$ & 0.00055 \\
$b_{W}$ & 3.06818 \\
\hline
\end{tabular}

regime shift (Albers and Anderson, 1985), to the present (2000). The fishery was "closed" when the estimated SSB dropped below a biomass-based management threshold (BBMT, defined below). Measurement errors in SSB were also incorporated, and were assumed to have a coefficient of variation (CV) of $20 \%$ based on the average historical variability for survey biomass estimates (Gustafson, 1994). Fishing mortality $(F)$ was assumed to be implemented without error, so that the effects of mis-specification in $R$ and $M$ could be better evaluated.

To investigate effects of harvest strategies on populations with different features, two models of $R$ were examined: (1) constant expected $R$ at the historical average value (608 million individuals); (2) a Beverton-Holt model with autocorrelated errors (simply called B-H):

$$
R_{t}=\frac{a S_{t-r}}{1+\beta S_{t-r}} e^{\phi \varepsilon_{t-1}+v_{t}}
$$

where $\phi \varepsilon_{t-1}$ is the first-order autocorrelation error term, and $v_{t} \sim N\left(0, \sigma^{2}\right)$. The simulation model included process errors associated with $R$, growth, and $M$. Both $R$ models include lognormal process errors with $\mathrm{CV}$ $(=\sigma)$ of $50 \%$ (Fig. 2). Growth variability is reflected in the mean length at recruitment $\left(\mu_{r, t}\right)$, which has a normal distribution with mean of $9.0 \mathrm{~mm}$ and standard deviation of $1.0 \mathrm{~mm}$. Two sets of $M$ were used. Because $M$ is commonly assumed to be constant for stock assessments and evaluations of management strategies, $M$ was set at 0.4 with a lognormal variation $(\mathrm{CV}=$ $20 \%$ ). A second $M$ model with a steadily increasing annual rate of 0.03 , starting with the mean of 0.4 , was employed (Fig. 2). Variability in $M$ was imposed with a CV of $20 \%$. Different random number seeds were used for $R, M$ and SSB for each run of 1000 replicates. The same random seeds were used for each scenario.

\section{Comparisons of $\boldsymbol{F}$ and BBMT levels}

Reference levels of SSB for a healthy stock have often referred to the virgin biomass $\mathrm{SSB}\left(\mathrm{SSB}_{0}\right)$, so we defined alternative levels of BBMT in terms of percentages of $\mathrm{SSB}_{0}$. A level of $20 \%$ of $\mathrm{SSB}_{0}$ has been considered as a threshold for recruitment overfishing (Beddington and Cooke, 1983; Quinn et al., 1990; Francis, 1993; Thompson, 1993). We defined $20 \%$ of $\mathrm{SSB}_{0}$ as the BBMT corresponding to a population-atrisk threshold. 

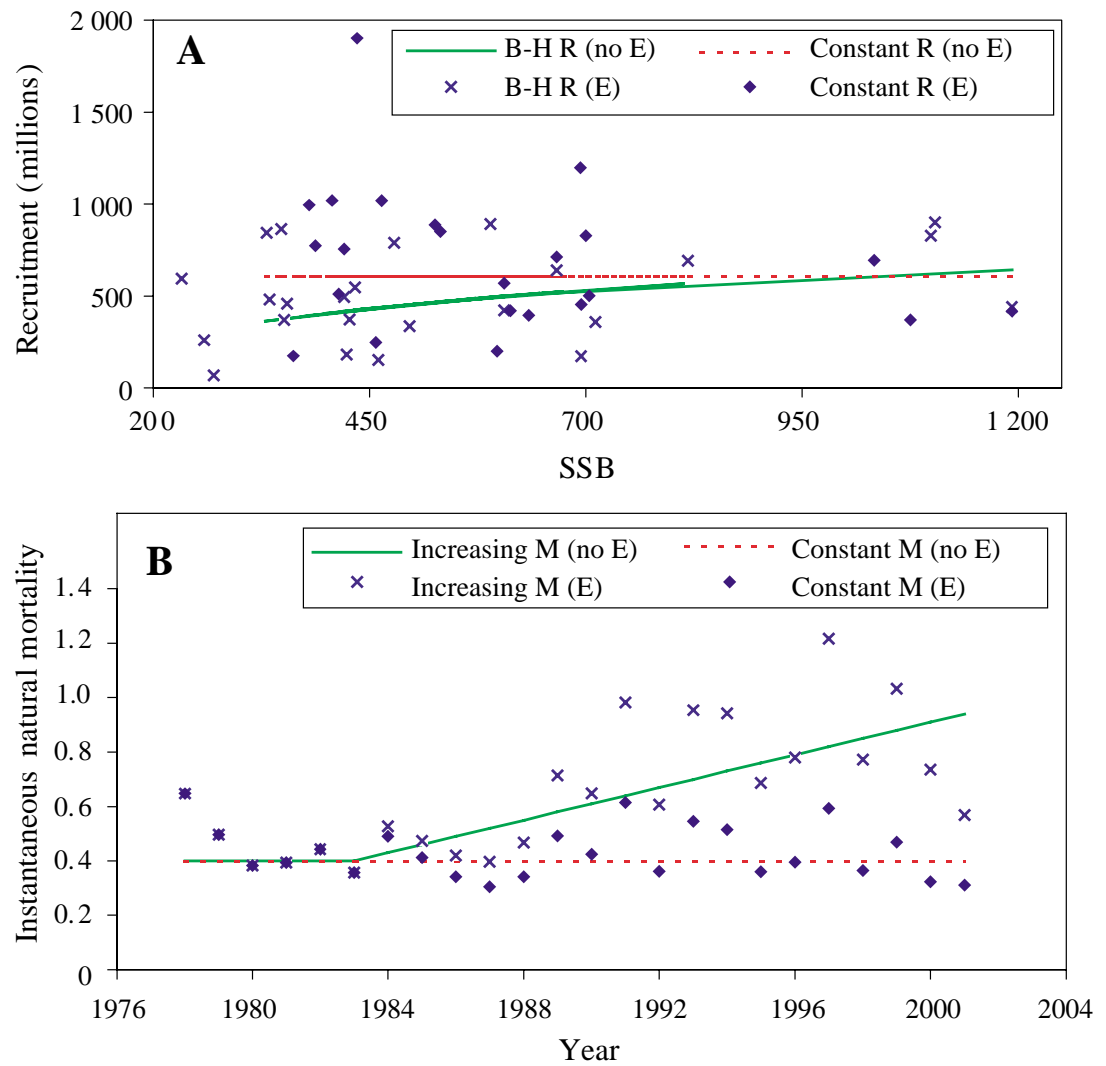

Fig. 2. (A) Constant (608 million) and B-H recruitment $(R)$ without lognormal errors ("no E"), and one random realization of constant and B-H R with lognormal errors ("E", $\mathrm{CV}=50 \%$ ). (B) Constant and increasing natural mortality $(M)$ without lognormal errors ("no E"), and one random realization of constant and increasing $M$ with lognormal errors ("E", $\mathrm{CV}=20 \%$ ).

Harvest strategies were simulated using six levels of constant $F$ ranging from 0.0 to 1.5 , and three levels of BBMT ranging from 0.0 to $40.0 \%$ of $\mathrm{SSB}_{0}$. Threshold management was implemented, i.e. the fishery was closed, when estimated population SSB level fell below BBMT. For each $F$ level, average risk was calculated as the percentage of 1000 replicates in which the population fell below the population-atrisk threshold $0.2 \mathrm{SSB}$. The optimal $F\left(F_{\text {opt }}\right)$ is generally defined as the value that maximizes yield while minimizing the risk of population decline, two contradictory objectives (Hollowed and Megrey, 1993). Therefore the following objective function $(f)$ was employed for calculating $F_{o p t}$ :

$$
f=\operatorname{Max}\left\{\frac{Y_{F}}{\operatorname{Max} Y}-R I S ._{F}\right\}
$$

where $Y_{F}$ is the cumulative yield over the 23 year simulation at a given $F$ level averaged over the 1000 replicates; $\operatorname{Max} Y$ is the maximum among $Y_{F}$; and $R f S K_{F}$ equals the average risk at a given $F$ level. If a set of $F$ and BBMT produces maximum yield but always drives the population SSB below the population-at-risk threshold, then the objective function has a value of 0.0 . The worst case has a value approaching -1.0 , and the best case has a value approaching 1.0 .

\section{Establishment of GLs for $F$}

The optimum choice of GLs for catch, effort or $F$ in advance of the fishery is dependent on knowledge about $R$ and annual $M$ during the coming year and present population abundance. In this paper, the annual length-based population assessment model was applied with the same objective function to determine an optimum GL for $F\left(F_{G L}\right)$. A flow chart illustrates the processes of population dynamics and the estimation of $F_{G L}$ (Fig. 3). It shows two lines of flow in the estimation of $F_{G L}$ starting with the survey. For 
simplicity, no measurement errors in survey biomass estimates are imposed. Therefore, if the survey takes place, our knowledge about the present population abundance status is updated to the true one. If not, then the population status is estimated based on previously specified $R$ and $M$. Therefore, the simulation results are the most optimistic possible. Based on the present population status and specified $R$ and $M$ for the following year, $F_{G L}$ is calculated and implemented, and the population reaches a new level. The second line of flow gives the true population abundance status and true parameters of $R$ and $M$ (i.e. $R_{\text {true, }, t}$ and $M_{\text {true }, t}$ ), from which true yield and risk are obtained after implementing $F_{G L}$. Values of $R_{\text {true, }}$ were generated using the $R$ models, the same parameter values, and the same lognormal errors as those described in the Stochastic Simulation section. Values of $M_{\text {true }}$ were generated using the constant expected value of 0.4 and lognormal errors with CV of $20 \%$. The population was simulated within a 100 -year time frame.

To examine the robustness of the $F_{G L}$ determination to the uncertainties in $R$ and $M, R$ and $M$ were purposely mis-specified in various ways. For $R$, two sets of values were specified with two constant expected means of 150 million and 3 billion individuals, below and above the true average of 608 million, and with lognormal errors $(\mathrm{CV}=50 \%)$. For $M I$ three sets of values were specified: 0.2 less than each $M_{\text {true, } t}$ (i.e. $\left.M_{\text {true, }}-0.2\right)$; a constant value of 0.4 for each year with no variation $(\mathrm{CV}=0 \%)$; and 0.2 more than each $M_{\text {true, } t}$ (i.e. $M_{\text {true, } t}+0.2$ ). The simulated population was surveyed once every 1 to 3 years for comparisons.

\section{Results}

\section{Effects of alternative constant fishing mortalities}

With the constant $R$ and $M$ model, SSB attained a stable level for each value of $F$ when BBMT was set at $0.0 \%$ of $\mathrm{SSB}_{0}$, i.e. no threshold management (Fig. 4). Cumulative yield steadily increased, and the risk of population SSB going below the population-at-risk threshold was high for $F$ at 0.9 and above. With BBMT set at $20 \%$ of $\operatorname{SSB}_{0}$ (260.0 tons), SSB was sustained slightly above the BBMT level for $F>0.6$ due to fishery closures. Risk declined as $F$ was reduced; and was low for $F<0.3$. A higher level of BBMT ( $40 \%$ of $\mathrm{SSB}_{0}$ ) helped the population sustain a higher SSB level and further reduced risk (not shown). On the other hand, as $M$ increased steadily from 0.4 to 0.9 , SSB dropped to low levels even with $F=0.0$ (Fig. 5). Threshold management reduced risk by helping to sustain SSB around the levels obtained under $F=0.0$, but the resultant fishery closures greatly reduced the total yield. Under either constant $M$ or increasing $M$, cumulative yield curves for $F=0.3$ were distinctively below other yield curves. This low level of $F$ does not seem to be profitable in any case in terms of fishery yield, and it did not stop the population from collapsing when $M$ increased to high levels.

When recruitment was a function of SSB with the B-H model, high $F$ such as 1.2 and 1.5 without threshold management wiped out the population completely even under constant $M$ (Fig. 6). Under such conditions, threshold management was critical to keep the population from extinction. At a low $F$ of 0.3 and constant $M$, SSB was sustained at a high level and there was no need for threshold management (Fig. 6). By the end of the 23 years, cumulative yield surpassed yields from scenarios of high $F>0.9$. Under the B-H $R$ model with increasing $M I \mathrm{SSB}$ declined below the population-at-risk threshold under any $F$ level (Fig. 7). Threshold management prevented complete extinction under high $F$. With increasing $M$, low $F$ led to low levels of cumulative yield and could not prevent population extinction when the $M$ level is high.

\section{Optimal constant fishing mortality}

In any one year, $F_{o p t}$ was not only related to the natural processes of recruitment and natural mortality, but also to previous management actions, such as $F$ and BBMT level. Table 2 shows the results for optimal $F$ as a function of the S-R model, $M$, and the BBMT level. Under the constant $M$ and $R$ model, cessation of fishing when the estimated SSB was below the BBMT of $20 \%$ of $\mathrm{SSB}_{0}$ increased the cumulative yield and reduced the average risk. Under increasing $M$, high $F$ is preferred, and the average risk was high even with a BBMT of $40 \%$ of $\mathrm{SSB}_{0}$. Threshold management reduced risk but at the cost of greatly reduced yield.

With the B-H $R$ model, as constant $M$ increased from 0.2 to $0.4, F_{\text {opt }}$ was lower under a BBMT of 0 or $20 \%$ of $\mathrm{SSB}_{0}$ compared to $F_{\text {opt }}$ under $40 \% \mathrm{SSB}_{0}$ (Table 2 ). When $M$ was 0.6 , optimal $F$ tended to be high, and the average risk was also very high in comparison. The model of increasing $M$ resulted in high average risk of population SSB going below the population-at-risk threshold (0.305) under continual harvesting at $F$ of 0.52 with no threshold management, and threshold management helped reduce the risk only to some extent. The high risk under increasing $M$ suggests that there is no way of protecting the population if $M$ truly increases over time. Optimal $F$ increases with BBMT 


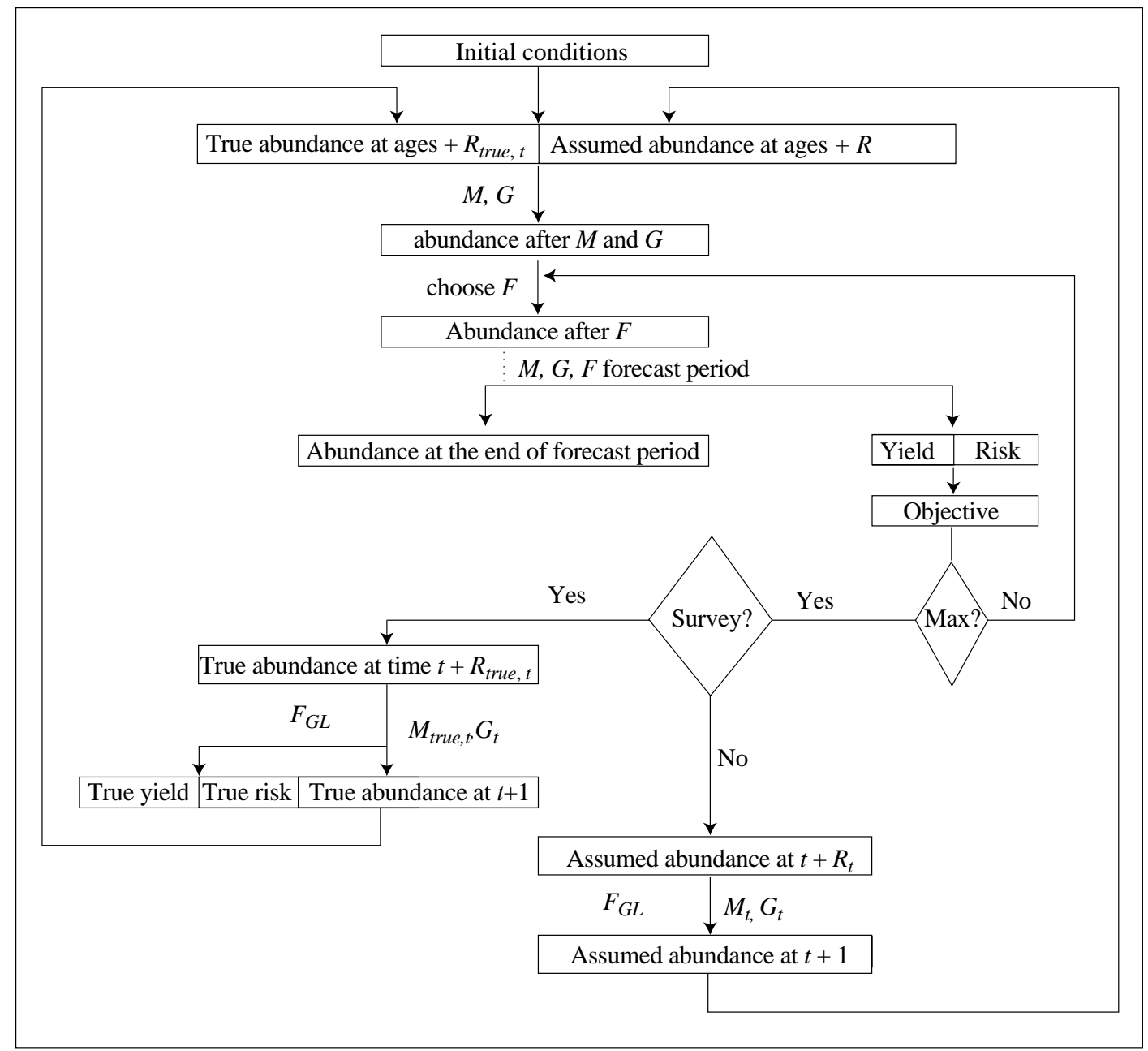

Fig. 3. Flow chart illustrating the annual setting process for guideline level for $F\left(F_{G L}\right)$; growth $G$ is assumed to be true; $R, M$ and $F$ denote assumed annual recruitment, instantaneous natural mortality and fishing mortality respectively; $R_{\text {true, } t}$ and $M_{\text {true, },}$ are the true underlying $R$ and $M$ levels.

levels that are examined. However, no general rules regarding the trend in cumulative yield and risk were found.

\section{Establishment of GL}

With the underlying true S-R relationship, the effectiveness of prescribing $F_{G L}$ was determined by the level of $M$ specified compared to its true value and the frequency of survey sampling (Fig. 8). When $M$ for each year was specified at 0.2 lower than $M_{\text {true, }}$ t (underestimated), and the population was sampled once every year, the cumulative yield was consistently higher than those obtained from scenarios with levels of $M$ equal to $M_{\text {true, },}$ or $M_{\text {true, } t}+0.2$. Nevertheless, cumulative risk, i.e. risk cumulated over the previous years, was also consistently higher. Despite the danger of falling below the population-at-risk threshold, the
SSB levels did not show any declining trend. When $M$ for year $t$ was fixed at the constant expected value of 0.4 without annual variations, cumulative yield was very close to that from the scenario of $M_{\text {true, }}$; however, risk was much higher in comparison. Risk from the scenario of $M_{\text {true, }}$ was 0.0 . On the other hand, specifying $M$ at a value of 0.2 higher than $M_{\text {true, }}$ (overestimation) reduces the cumulative yield, but keeps the population under very low or no risk of population SSB going below population-at-risk threshold.

Sampling frequency has no effect on management and population response to exploitation if $M$ is accurately known, but it plays an important role when $M$ is mis-specified, and especially when $M$ is specified too low. Under the scenario in which $M$ is 0.2 lower 

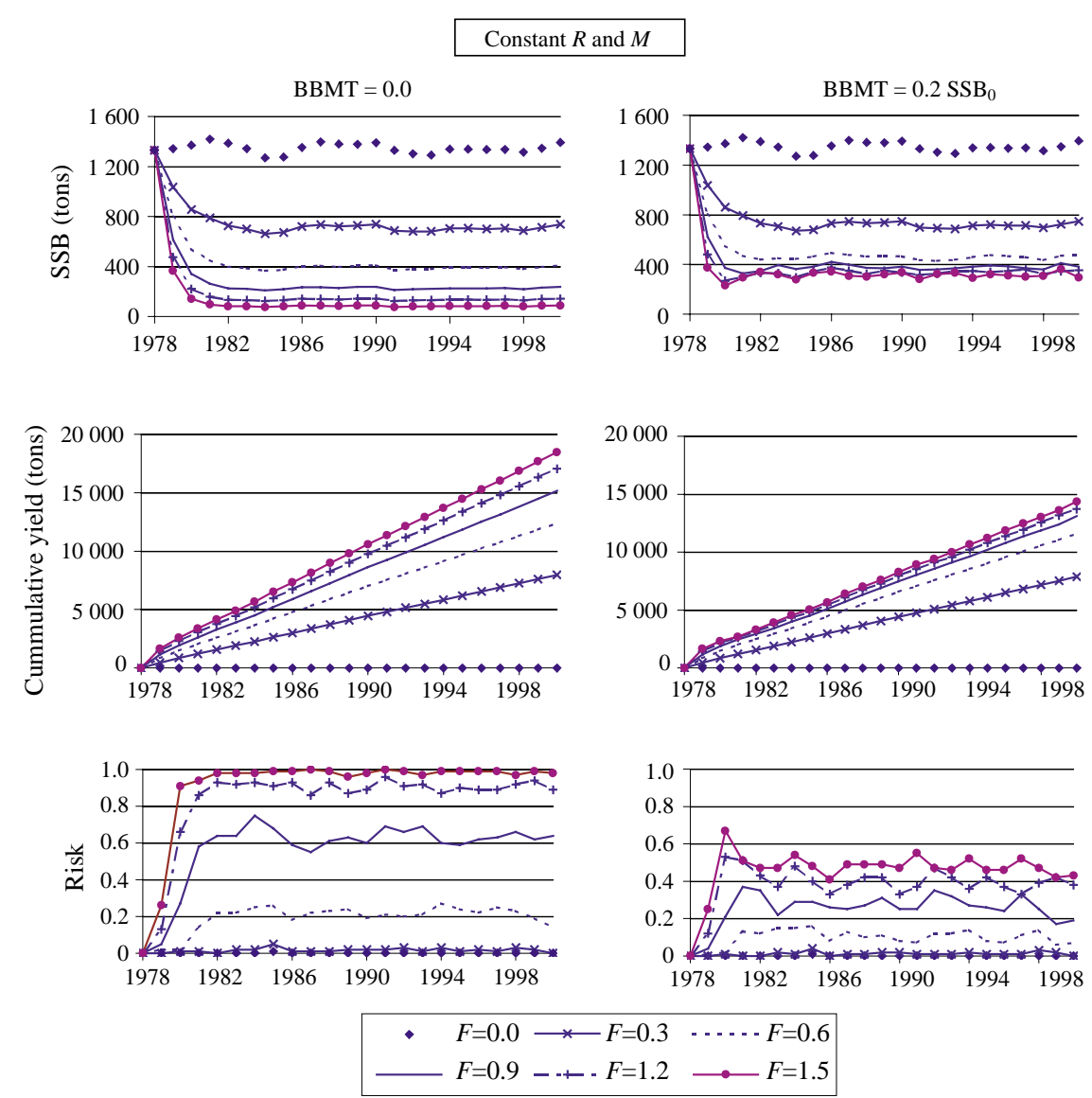

Fig. 4. Comparisons of spawning stock biomass (SSB), cumulative yield and risk over time from 6 levels of fishing mortality $(F)$ (within panel) and 2 levels of biomassbased management threshold (BBMT $=0.0$ and 260.0) (between columns) under constant recruitment $(R)$ and natural mortality $(M)$.

than $M_{\text {true, } t}$, the risk of population SSB going below the population-at-risk threshold increases when the population is sampled only once every 2 or 3 years. Compared with sampling once every 2 years, sampling once every 3 years results in lower yield as well as higher risk. The population is gradually wiped out as time progresses.

Under the situation of $M_{\text {true, }}$, the accuracy of prescribing $F_{G L}$ is more dependent on the survey sampling frequency than on the $R$ levels assumed (Fig. 9). If the population is sampled once every year, setting recruitment at either below the true average (i.e. 150 million) or above the true average (i.e. 3 billion) results in similar yield and risk levels. However, when the population is sampled once every 3 years, specifying $R$ too high produces much higher yield and risk, as well. SSB is quickly depleted and remains at a very low level for several decades.
Nevertheless, fishery closures and a period of favorable recruitment (despite low SSB) bring the population back to relatively high levels for a few years (years 1970 to 1985). In contrast, when $R$ is at the level of 150 million, sampling once every 3 years did not produce an adverse effect on yield and risk, although the SSB became quite variable.

\section{Discussion}

When $M$ was fixed at the mean expected value (0.4), the simulated northern shrimp population in Kachemak Bay was sustainable under an $F_{\text {opt }}$ harvest policy. However, with an increasing $M$ trend (which is the more likely case as shown in Fu et al. (1999)) with the same expected mean value, high risk resulted under the $\mathrm{B}-\mathrm{H} R$ model. Thus, the importance of $M$ trends to stock assessment and fishery management issues is concealed when $M$ is fixed as commonly practiced. 

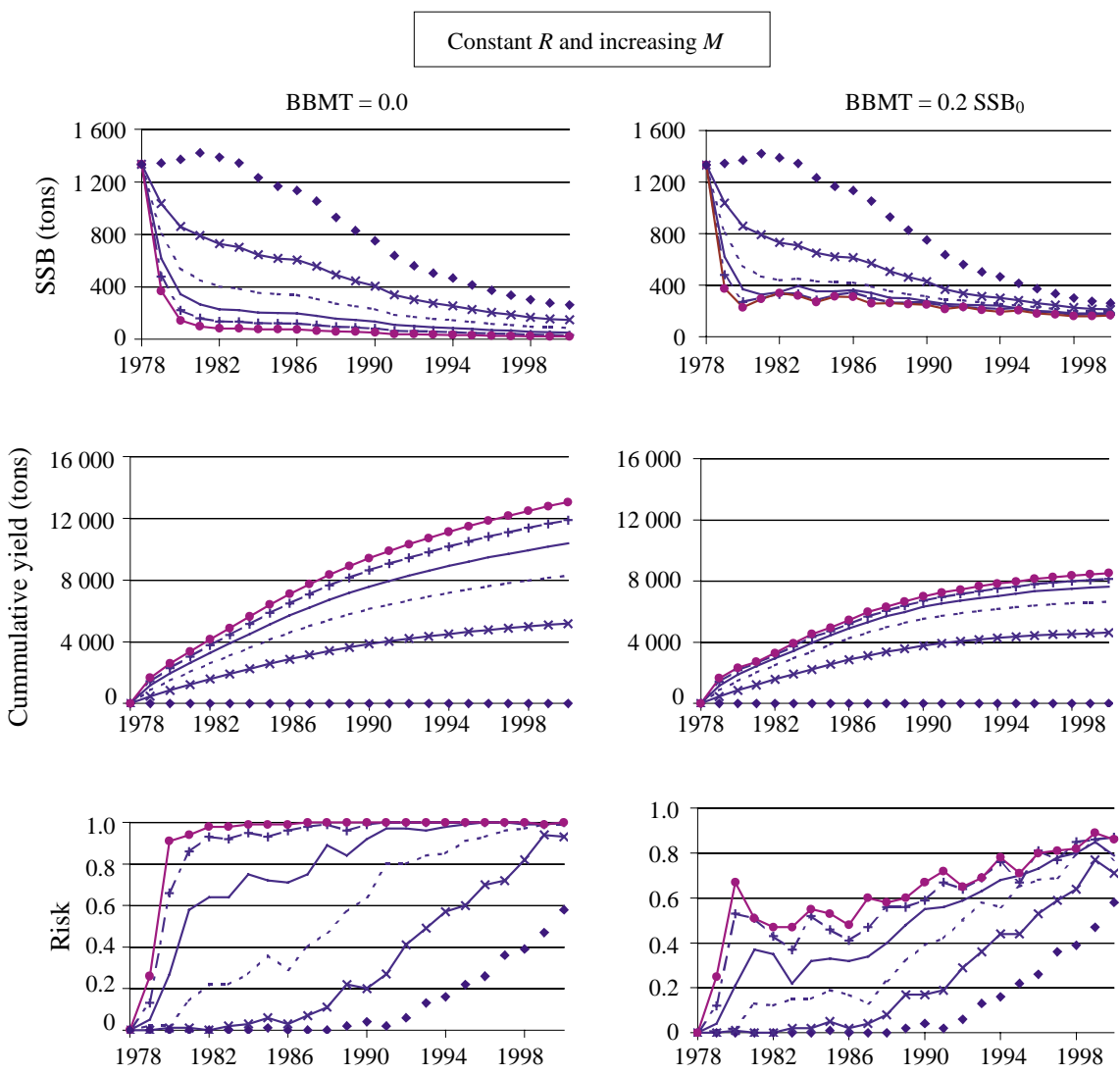

$$
\begin{aligned}
F=0.0 \longrightarrow *-F=0.3 & \ldots \ldots F=0.6 \\
F=0.9--+F=1.2 & \ldots F=1.5
\end{aligned}
$$

Fig. 5. Comparisons of spawning stock biomass (SSB), cumulative yield and risk over time from 6 levels of fishing mortality $(F)$ (within panel) and 2 levels of biomassbased management threshold (BBMT $=0.0$ and 260.0) (between columns) under constant recruitment $(R)$ and increasing natural mortality $(M)$.

Francis (1993) demonstrated that acceptable harvesting levels depended more strongly on $R$ than on $M$ when $M$ was fixed. The assumption about constant $M$ may not be valid for some populations. For example, for the red king crab population in Bristol Bay, Alaska, Zheng et al.(1997) showed that mortality rate increased sharply for a few years in the early-1980s before returning to lower levels in the mid-1980s. Realistic assumptions about $M I$ particularly about its time trend, are desirable to accurately evaluate harvest strategies.

Biological reference points are traditionally drawn from yield-per-recruit analysis, but assumptions about constant $R$ is likely to be unrealistic, particularly for populations that drop to very low levels. For this population, constant $R$ rendered drastically different consequences from other $R$ models, such as $\mathrm{B}-\mathrm{H}$, when the population was exploited under high $F$ or when it experienced high $M$. With constant $R$, the population was sustainable even under high $F$ or high $M$. Therefore, for a population with $M$ increasing over time, realistic $R$ models are necessary.

Except for the unrealistic scenario with constant $M$ and $R$, all scenarios required threshold management to prevent complete population collapse under high $F$. We used $20 \%$ of $\mathrm{SSB}_{0}$ as a proxy for the populationat-risk threshold. However, the true stock level at which recruitment to a population will decline rapidly is not knowable until after it happens (Botsford et al., 1997), after which it may be too late to reverse the population decline. Arbitrary measures, such as $20 \%$ of $\mathrm{SSB}_{0}$ or even a more conservative level, are 

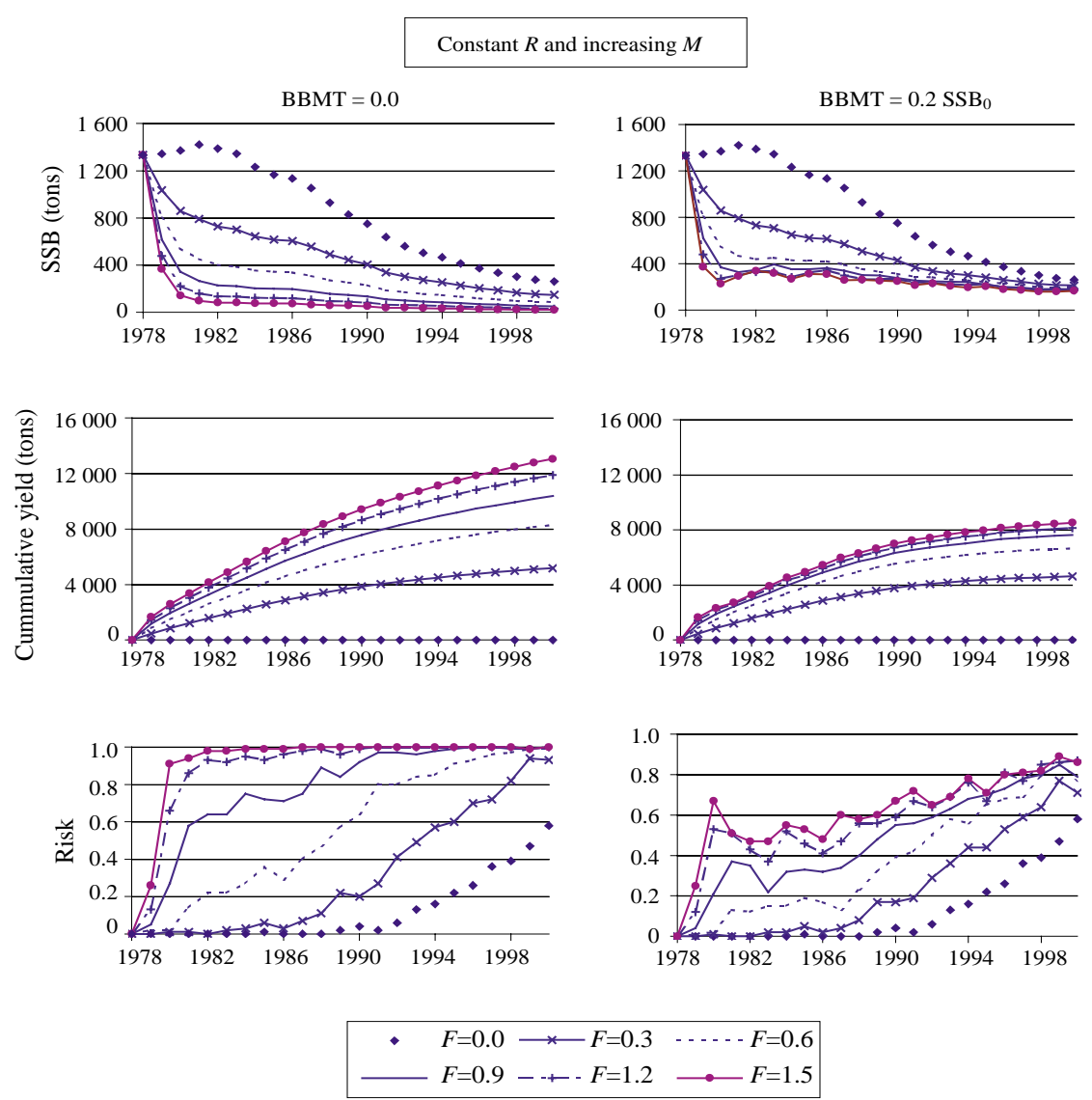

Fig. 6. Comparisons of spawning stock biomass (SSB), cumulative yield and risk over time from 6 levels of fishing mortality $(F)$ (within panel) and 2 levels of biomassbased management threshold (BBMT $=0.0$ and 260.0) (between columns) under $\mathrm{B}-\mathrm{H}$ recruitment $(R)$ and constant natural mortality $(M)$.

necessary to implement threshold management using a precautionary approach.

For some scenarios a threshold may not be necessary. For instance, with the B-H $R$ model and constant $M$, the shrimp population was sustained above BBMT level when fished at an $F_{\text {opt }}$. Zheng et al. (1997) illustrated that a threshold had little effect on yield and spawning biomass variability when a fishery had handling mortality of discards of $20 \%$ or less, but a threshold was important to protect the population when handling mortality rates as high as $50 \%$. Haist et al. (1993) also concluded from simulation studies that there was no requirement for a threshold spawning stock biomass for exploitation rates below 0.4 under the assumption of constant $M$. Nevertheless, under increasing $M$ or low $R$, threshold management appears to help prevent the population from extinction, so is desirable as a Precautionary Approach when ecosystem changes occur.
Under the B-H $R$ model and constant expected $M$ levels of 0.2 and 0.4 , the population was sustained under an average $F$ of 0.56 and 0.36 , respectively. However, our results of constant $F_{\text {opt }}$ under the situations of increasing $M$ or constant expected $M$ level of 0.6 should be viewed cautiously, because there is essentially no feedback in the analyses. Ideally, in most cases $F_{\text {opt }}$ should be estimated annually based on population monitoring results.

The establishment of GL for $F$ is an essential ingredient in evaluating harvest strategies. Its validity is dependent upon the estimation of present population status and that of $M$ and $R$ in the following year. When population abundance is estimated every year without measurement error, mis-specification of $R$ has very little effect on the forecast, but underestimation of $M$ can increase the risk that the population falls below the population-at-risk threshold. Therefore, a good understanding of $M$ is more important than that of $R$. 

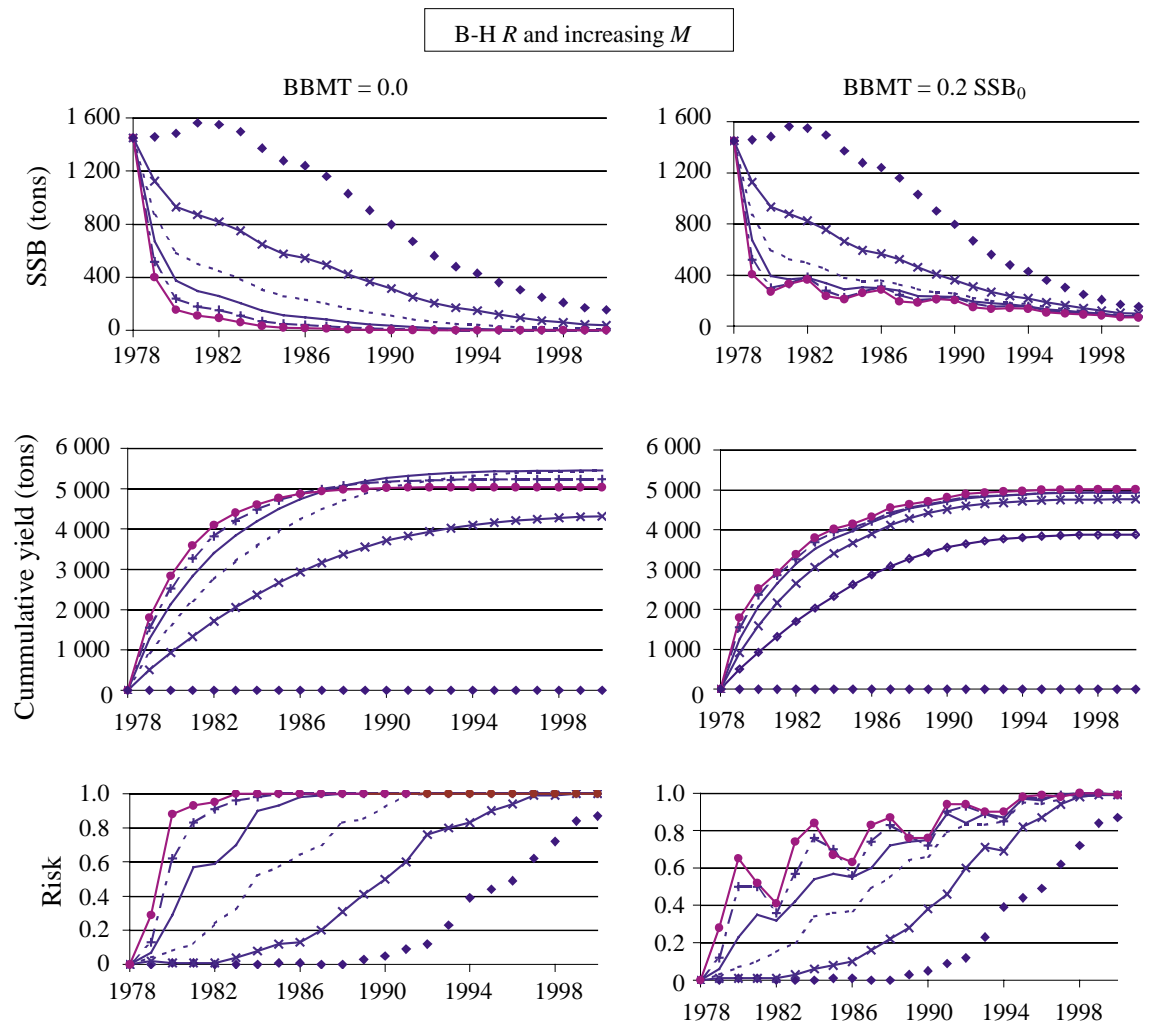

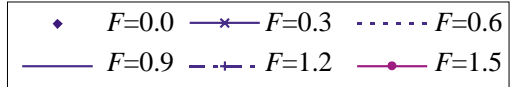

Fig. 7. Comparisons of spawning stock biomass (SSB), cumulative yield and risk over time from 6 levels of fishing mortality $(F)$ (within panel) and 2 levels of biomassbased management threshold (BBMT $=0.0$ and 260.0) (between columns) under $\mathrm{B}-\mathrm{H}$ recruitment $(R)$ and increasing natural mortality $(M)$.

TABLE 2. Optimal fishing mortality $\left(F_{\text {opt }}\right)$, objective function value $(f)$, maximum yield (MaxY, units of $t$ ) and risk of population SSB going below population-at-risk threshold $\left(20 \%\right.$ of $\left.\mathrm{SSB}_{0}\right)$ averaged over the entire time period corresponding to different $R$ and $M$ models and biomass-based management threshold (BBMT) levels (defined as percentage of virgin SSB) under constant $F$.

\begin{tabular}{|c|c|c|c|c|c|c|}
\hline $\mathrm{S}-\mathrm{R}$ & $M$ & BBMT(\%) & $F_{o p t}$ & $f$ & $\operatorname{Max} Y$ & Risk \\
\hline Constant $R$ & $M=0.4$ & 0 & 0.65 & 0.59 & 12587 & 0.092 \\
\hline Constant $R$ & $M=0.4$ & 20 & 0.80 & 0.80 & 12655 & 0.087 \\
\hline Constant $R$ & $M=0.4$ & 40 & 1.5 & 0.90 & 11771 & 0.096 \\
\hline Constant $R$ & Increasing $M$ & 0 & 1.5 & 0.57 & 13203 & 0.431 \\
\hline Constant $R$ & Increasing $M$ & 20 & 1.5 & 0.71 & 8602 & 0.293 \\
\hline Constant $R$ & Increasing $M$ & 40 & 1.5 & 0.83 & 6404 & 0.173 \\
\hline B-H $R$ & $M=0.2$ & 0 & 0.56 & 0.995 & 21489 & 0.003 \\
\hline B-H $R$ & $M=0.2$ & 20 & 0.58 & 0.996 & 21510 & 0.004 \\
\hline B-H $R$ & $M=0.2$ & 40 & 0.80 & 0.999 & 21393 & 0.001 \\
\hline B-H $R$ & $M=0.4$ & 0 & 0.36 & 0.88 & 7623 & 0.054 \\
\hline B-H $R$ & $M=0.4$ & 20 & 0.42 & 0.91 & 7722 & 0.044 \\
\hline B-H $R$ & $M=0.4$ & 40 & 0.80 & 0.95 & 7887 & 0.051 \\
\hline B-H $R$ & $M=0.6$ & 0 & 0.44 & 0.599 & 2698 & 0.394 \\
\hline B-H $R$ & $M=0.6$ & 20 & 1.5 & 0.619 & 2620 & 0.381 \\
\hline B-H $R$ & $M=0.6$ & 40 & 1.5 & 0.780 & 1747 & 0.220 \\
\hline B-H $R$ & Increasing $M$ & 0 & 0.52 & 0.66 & 5506 & 0.305 \\
\hline B-H $R$ & Increasing $M$ & 20 & 0.52 & 0.67 & 4931 & 0.288 \\
\hline B-H $R$ & Increasing $M$ & 40 & 1.0 & 0.76 & 4373 & 0.194 \\
\hline
\end{tabular}



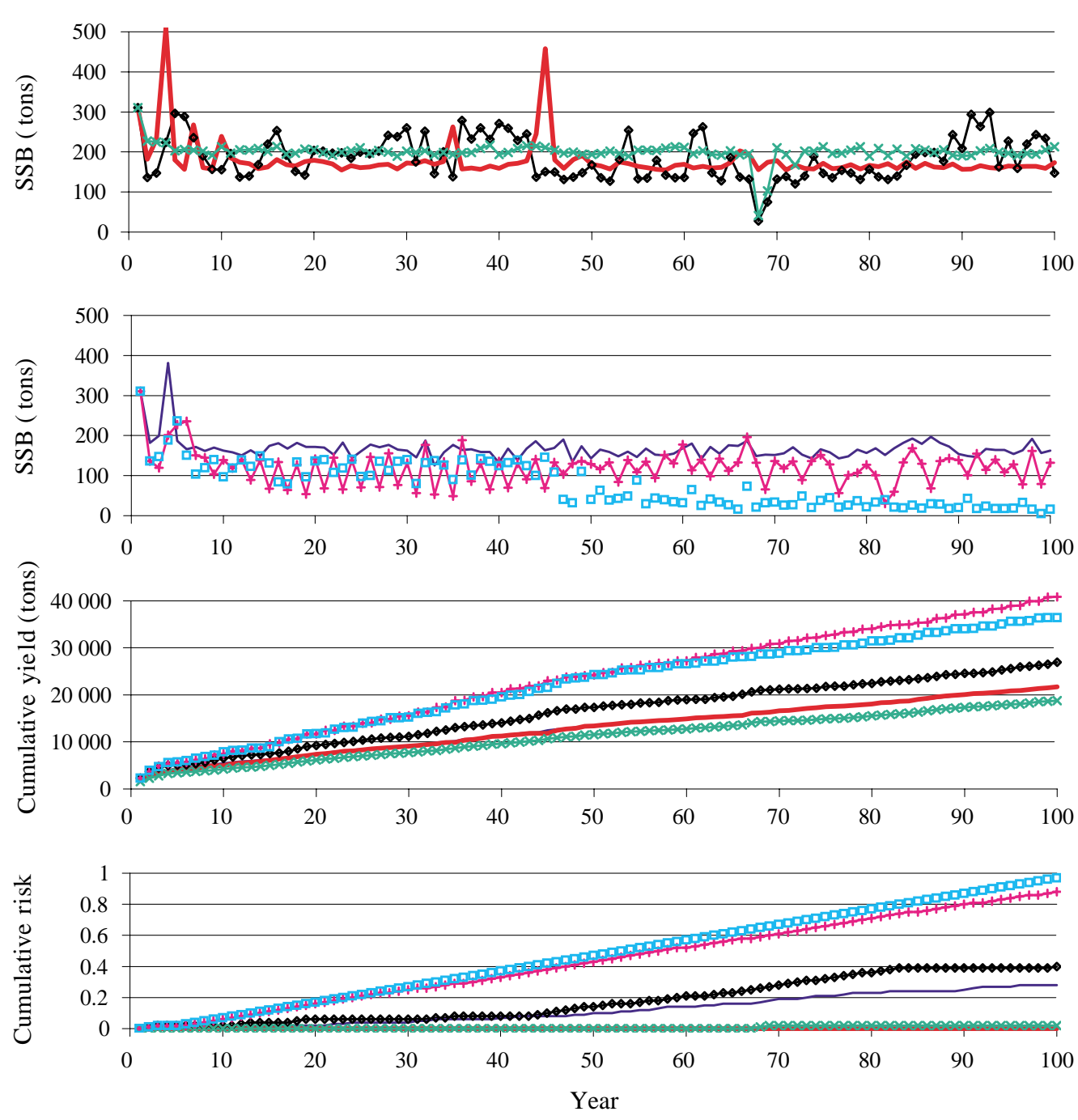

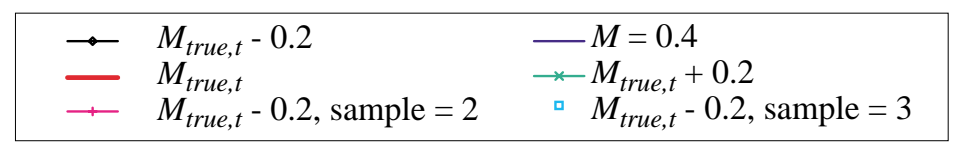

Fig. 8. Comparisons of spawning stock biomass (SSB) (Panels 1 and 2), cumulative yield and risk from guideline levels for $F\left(F_{G L}\right)$ obtained under $\mathrm{R}_{\text {true }, t}$, four levels of $M\left(0.2\right.$ less than $M_{\text {true, },}$, constant at $0.4, M_{\text {true, },}, 0.2$ more than $M_{\text {true, } t}$ ) and two additional sampling frequencies (sampling once every 2 and 3 years) with $M_{\text {true, } t}-0.2$.

When sampling occurs only once every 2 or 3 years, overestimation of $R$ or underestimation of $M$ deteriorates the conservation benefits of the fishery management strategy. Therefore, we emphasize the need for routine annual research surveys to obtain estimates of population abundance and parameters, at least during periods when the fishery is being prosecuted. As a final note of caution, our analysis did not include survey measurement errors nor errors in implementing the preseason $F_{G L}$. The performance of the strategies we analyzed will be reduced given such errors. Survey data accuracy is critical for forecasting stock dynamics and prescribing $F_{G L}$.

\section{Acknowledgments}

This publication is the result of research sponsored by Alaska Sea Grant with funds from the National Oceanic and Atmospheric Administration, Office of Sea Grant, Department of Commerce, USA (grant 

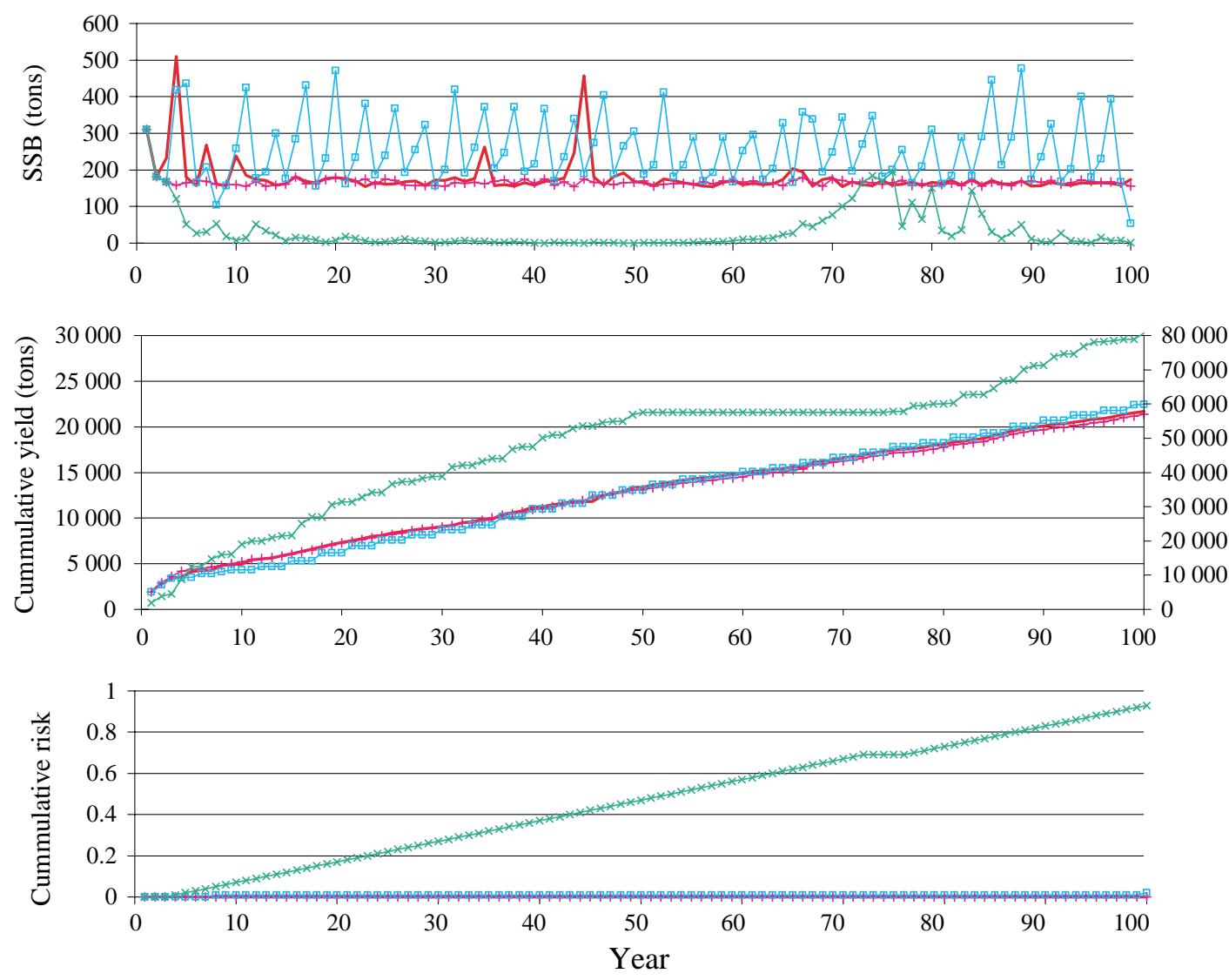

\begin{tabular}{|c|c|}
\hline $\begin{array}{l}-M, R_{\text {true }, t, \text { sample }=3} \\
-M_{\text {true }, t, R}, 150 \text { million, sample }=3\end{array}$ & $\begin{array}{ll}\text { — } & M_{\text {true }, t,} R=3 \text { billion, sample }=1 \\
- & M_{\text {true }, t} R=3 \text { billion, sample }=3\end{array}$ \\
\hline
\end{tabular}

Fig. 9. Comparisons of spawning stock biomass (SSB), cumulative yield and risk from guideline levels for $F\left(F_{G L}\right)$ obtained under $M_{\text {true, } t}$ and sampling every 3 years, three levels of $R$ (150 million, $R_{\text {true, } t}, 3$ billion), and one additional sampling frequency (sampling every year) with $R$ of 3 billion.

NA90AA-D-SG066, projects R/07-21 and R/31-03) and from the University of Alaska. We appreciate valuable comments from two referees, Gunnar Stefansson and Bob Mohn. Comments by Milo Adkison also resulted in improvement to the paper.

\section{References}

ALBERS, W. D., and P. J. ANDERSON. 1985. Diet of Pacific cod, Gadus macrocephalus, and predation on the northern pink shrimp, Pandalus borealis, in Pavlof Bay, Alaska. Fish. Bull., 83: 601-610.

BECHTOL, W. R. 1997. Changes in forage fish populations in Kachemak Bay, Alaska, 1976-1995. In: Forage fishes in marine ecosystems, proceedings of the international symposium on the role of forage fishes in marine ecosystems. Alaska Sea Grant Report 97-01, University of Alaska Fairbanks, p. 441-456.

BEDDINGTON, J. R., and J. COOKE. 1983. The potential yield of previously unexploited stockes. FAO Fish.Tech.
Pap., No. 242, 47 p.

BOTSFORD, L. W., J. C. CASTILLA, and C. H. PETERSON. 1997. The management of fisheries and marine ecosystems. Science, 277: 509-515.

CLARK, W. G. 1991. Groundfish exploitation rates based on life history parameters. Can. J. Fish. Aquat. Sci., 48: 734-750.

DAVIS, A. S. MS 1982. The commercial otter trawl shrimp fishery of Cook Inlet. Alaska Department of Fish and Game, Division of Commercial Fisheries, Information Leaflet, No. 205, Juneau.

FRANCIS, R. I. C. C. 1993. Monte Carlo evaluation of risks for biological reference points used in New Zealand fishery assessments. In: Risk evaluation and biological reference points for fisheries management. S.J. Smith, J.J. Hunt, ankd D. Rivard (eds.). Can. Spec. Publ. Fish. Aqua. Sci., 120: 221-230.

FU, C., T. J. QUINN, II, and M. D. ADKISON. 1999. Retrospective projection using Monte Carlo simulation: An application of a length-based model to Kachemak Bay 
pink shrimp. In: Ecosystem approaches for fisheries management. Alaska Sea Grant Report 99-01, University of Alaska Fairbanks, p. 59-77.

GUSTAFSON, R. 1994. Trawl shrimp index fishing in the southern district of the Cook Inlet management area (spring 1992 and 1993). Alaska Department of Fish and Game, Division of Commercial Fisheries, Regional Information Report No. 2A94-23, Anchorage.

HAIST, V., D. A. FOURNIER, and J. F. SCHWEIGERT. 1993. Estimation of density-dependent natural mortality in British Columbia herring stocks through SSPA and its impact on sustainable harvesting strategies. In: Risk evaluation and biological reference points for fisheries management. S.J. Smith, J.J. Hunt, and D. Rivard (eds.). Can. Spec. Publ. Fish. Aquat. Sci., 120: 269-282.

HOLLOWED, A. B., and B. A. MEGREY. 1993. Harvest strategies for Gulf of Alaska walleye pollock. In: Proceedings of the international symposium on management strategies for explored fish populations. G. H. Kruse, D. M. Eggers, R. J. Marasco, C. Pautzke, and T. J. Quinn II (eds.). Alaska Sea Grant Report 9302, University of Alaska Fairbanks, p. 291-320.

ORENSANZ, J. M., J. ARMSTRONG, D. ARMSTRONG, and R. HILBORN. 1998. Crustacean resources are vulnerable to serial depletion - the multifaceted decline of crab and shrimp fisheries in the Greater Gulf of Alaska. Rev. Fish. Biol. Fish., 8: 117-176.
QUINN, T. J., II, R. FAGEN, and J. ZHENG. 1990. Threshold management policies for exploited populations. Can. J. Fish. Aquat. Sci., 47: 2016-2029.

QUINN, T. J., II, C. T. TURNBULL, and C. FU. 1998. A length-based population model for hard-to-age invertebrate populations. In: Fishery Stock Assessment Models. F. Funk, T. J. Quinn II, J. Heifetz, J. N. Ianelli, J. E. Powers, J. F. Schweigert, P. J. Sullivan, and C.-I. Zhang (eds.). Alaska Sea Grant Report 98-01, University of Alaska Fairbanks, p. 531-556.

SIGLER, M. F., and J. T. FUJIOKA. 1993. A comparison of policies for harvesting sablefish, Anoplopoma fimbria, in the Gulf of Alaska. In: Proceedings of the international symposium on management strategies for explored fish populations. G. H. Kruse, D. M. Eggers, R. J. Marasco, C. Pautzke, and T. J. Quinn II (eds.). Alaska Sea Grant Report 93-02, University of Alaska Fairbanks, p. 7-19.

THOMPSON, G. G. 1993. A proposal for a threshold stock size and maximum fishing mortality rate. In: Risk evaluation and biological reference points for fisheries management. S.J. Smith, J.J. Hunt, and D. Rivard (eds.). Can. Spec. Publ. Fish. Aqua. Sci., 120: 303-320.

ZHENG, J., M. C. MURPHY, and G. H. KRUSE. 1997. Analysis of harvest strategies for red king crab, Paralithodes camtschaticus, in Bristol Bay, Alaska. Can. J. Fish. Aquat. Sci., 54: 1121-1134. 